\title{
PSYCHE.
}

\section{AN INTERESTING BLOOD-SUCKING GNAT OF THE FAMILY CHIRONOMIDAE.}

BY C. H. TYleR TOWNSEND, LAS CRUCES, N. MEX.

While breaking camp the past summer, on the Continental Divide in western New Mexico, at a point about 6 miles west of Patterson, in the western part of Socorro county, I noticed a small gnat in some numbers on the horses. This was on the morning of June 2ist. The gnats were very small and black, but their abdomens being distended and swollen with blood gave them a red appearance. They were found mostly on the head and face, particularly around and below the eyes of the animals. A few specimens were hurriedly put in alcohol at the time. The altitude of this place was something over 7000 feet.

Quite recently, while attempting to determine these gnats, I found at first some difficulty in satisfying myself as to their family position. I believe now, however, that they properly belong in the Chironomidae. In their venation, they much resemble the section Anaretina, provisionally located by Loew and Osten Sacken in the Cecidomyiidae. The hind tibiae, however, have distinct terminal spurs, which is about the only character that would exclude them from that section. In this character, they would approach the Mycetophilidae, but the venation (see Pl. 8, fig. 2) is so decidedly cecidomyiid in its character as to preclude this idea. There are six longitudinal veins, the fifth vein is forked, and the fourth is to the best of my perception also forked; there are no cross-veins whatever. In their general aspect, and the consensus of their characters, they approach the genus Ceratopogon of Meigen; and also the genus Oecacta of Poey, which latter was erected for a small blood-sucking gnat in Cuba, known to the inhabitants of that country as "El jejen." The antennae of the present form are $\mathrm{I} 3$ - jointed $(\%)$, and the palpi are only 3 -jointed (see fig. I of plate). While the venation is more cecidomyiid than that of Oecacta, the general form of the body, as well as that of Ceratopogon, is quite the same. The lancets and labium are much the same in structure. The palpi are quite similar, except that Oecacta may be said to have two additional joints more at the end, and Ceratopogon 
one. There is quite an important difference between Oecacta and the present form in the shape of the eyes, which in the latter are reniform or deeply hollowed out on the inside margin, the antennae being set in a cavity partially enclosed by the excavated orbit. In this respect it resembles Simulium and most of the Cecidomyiidae and Chironomidae. Judging from the plate (see plate 27 of Poey's Memoirs on the Nat. Hist. of (uba, vol. I), Oecacta does not possess this peculiarity. Ceratopogon has the palpi 4 -jointed, and the conformation of the antennae is peculiar, especially in the $\delta$. It must be remembered that I have only $q$ specimens of the present species, and that the antennae of the $\delta$ may or may not be differentiated in form.

The present form, with the genera Ceratopogon (including Heteromyia Say) and Oecacta, possibly also Diamesa, differ to quite an extent from the rest of the Chironomidae. As a group, they nearly approach the Anaretina in their venation, the present genus showing the greatest resemblance in this respect, and differ from the other Chironomidae by the body and wings being shorter and stouter, not culicidlike or elongate and narrowed, as in Chironomus, Tanypus, et al. The venation is simpler; and the lancets and labium are more elongate, and about equal in length.

The form here figured differs so obviously from those genera already described that there seems no question of the advisability of making it the type of a new genus, which I shall call Ter-

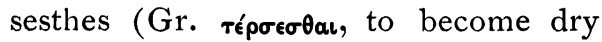
or thirsty). Its characters are as follows :

\section{Tersesthes nov. gen. $q$ (see plate 8 ).}

Antennae 13-jointed, set in large circular excavations in the middle of the head; first joint largest, round; second joint more elongate, smaller, but larger than following joints; last joint elongate conical ; intermediate ten joints equal, sub-moniliform, with hairs somewhat shorter than width of joints. Palpi 3-jointed, longer than proboscis, first joint shortest, second joint swollen, third narrow with a terminal whorl of hairs; proboscis consisting of a lower lip (labium), with the lancets free but usually more or less approximated to its anterior aspect, both of equal length, extended straight downward, about as long as the head, lancets serrate on outer edge at tip. No ocelli. Eyes reniform, rather deeply excavated on inside margin, dichoptic, front averaging one-third width of head. Thorax moderately stout, but not humped, a little wider than head, longer than wide, without transverse suture, scutellum prominent. Abdomen 7 -jointed, somewhat elongate, not wider than thorax, first three segments subequal, fourth smaller, three terminal segments narrowed; ovipositor exserted, consisting of two clavate pieces joined laterally on basal half and terminally divergent. Wings moderately broad, not elongate, hind margin with a delicate fringe of hairs, surface sparsely clothed with very short microscopic hairs (revealed only with a high objective); six longitudinal veins, the first and second approximated, strongest, ending at about one-third the length of wing; third gently curved distally and ending near the wing apex, fourth apparently forked, fifth distinctly forked, sixth becoming obsolete before fork of fifth; an apparent rudiment of a seventh vein; no cross-veins, except one 
at extreme base of wing which connects the first and sixth veins, marginal vein not extending beyond tip of wing. Legs slender, not dilated, coxae not elongate; hind tibiae spurred, middle and even front tibiae with microscopic spurs; metatarsi elongate, second joint of hind tarsi also elongate, of middle tarsi somewhat elongate, of front tarsi scarcely so, penultimate tarsal joint of all the feet shortened, the last and antepenultimate joints about equal; no pulvilli.

Tersesthes torrens n. sp. ㅇ.-General color blackish. Eyes dark brown; antennal excavations cinnamon colored, nearly three times the diameter of first antennal joint; front, face, and lancets shining black, the front with four blackish hairs on vertical margin arising from four papillae; antennae black, clothed with whitish pubescence; palpi blackish, labium brownish with some whitish pubescence terminally; occipital orbits with a few black hairs. Thorax and scutellum deep shining black, smooth, glabrous, except that the thorax has some scattered black hairs anteriorly. Abdomen soft opaque brown, varying to light brown, in some of the specimens flavous or rufous at base; balsam mount showing two oval black spots (bodies?) at base of fifth segment; ovipositor brownish. Legs blackish, tarsi brownish, tibiae slightly so. Wings grayish hyaline, with hardly a smoky flavous tinge, the delicate fringe of hind margin somewhat longest on anal angle where it terminates abruptly; veins pale, except first and second longitudinal veins which are brown and end in a brown stigma on costal margin (the first vein becomes obsolete just before reaching stigma); halteres brownish, knobs whitish.

Length of body (incl. ovipositor), I 3-5 $\mathrm{mm}$. (empty) to 2 I-5 mm. (abdomen distended with blood); of wing, I I-5 $\mathrm{mm}$. Fresh and alcoholic specimens are slightly longer. Described from both dried and alcoholic specimens, and balsam mounts. Six specimens collected, June $2 \mathrm{I}$, on Continental Divide, Socorro county, N. M., $7000 \mathrm{ft}$. This gnat was not observed at any other place than the one above named.

Note.-It should be stated that what I have called the first longitudinal vein is the auxiliary vein of other families. I have been in doubt whether to describe the wing as having five, or six, longitudinal veins, since the first two in the balsam mount show only as the sides of a single vein. Since, however, they appear in the dry wing, with a low power, as two distinct veins, I have so considered them, and have made the drawing of the wing to represent this appearance.

\section{Explanation of Plate 8.}

Tersesthes torrens Twns. ․

Fig. I.-Head, front view, showing lancets, labium, palpi, antennae, antennal excavations, and reniform eyes.

Fig. 2.-Wing. (It should be stated that the stigma does not show in the balsam mount as represented in the figure, but there is a slighter, more general infuscation in the region of the first two veins.)

Fig. 3.-Abdomen, dorsal view, showing ovipositor, two oval black bodies of fifth segment, and a large irregular contained body (mostly in second and third segments), probably the alimentary canal distended with blood.

Fig. 4.-Hind leg, with coxa attached.

Fig. 5.-Middle leg.

Fig. 6.-Front leg.

Figs. 2 to 6 are enlarged on the same scale. Fig. I is still more greatly enlarged. The hair lines accompanying figs. I to 3 show the natural size. The drawings were all made from balsam mounts, and outlined with the camera lucida. The scanty material in $\mathrm{my}$ possession prevents the figuring at the present time of the component pieces which form the lancets. 
Psyche, 1892, vol. 6.

Plate 8.

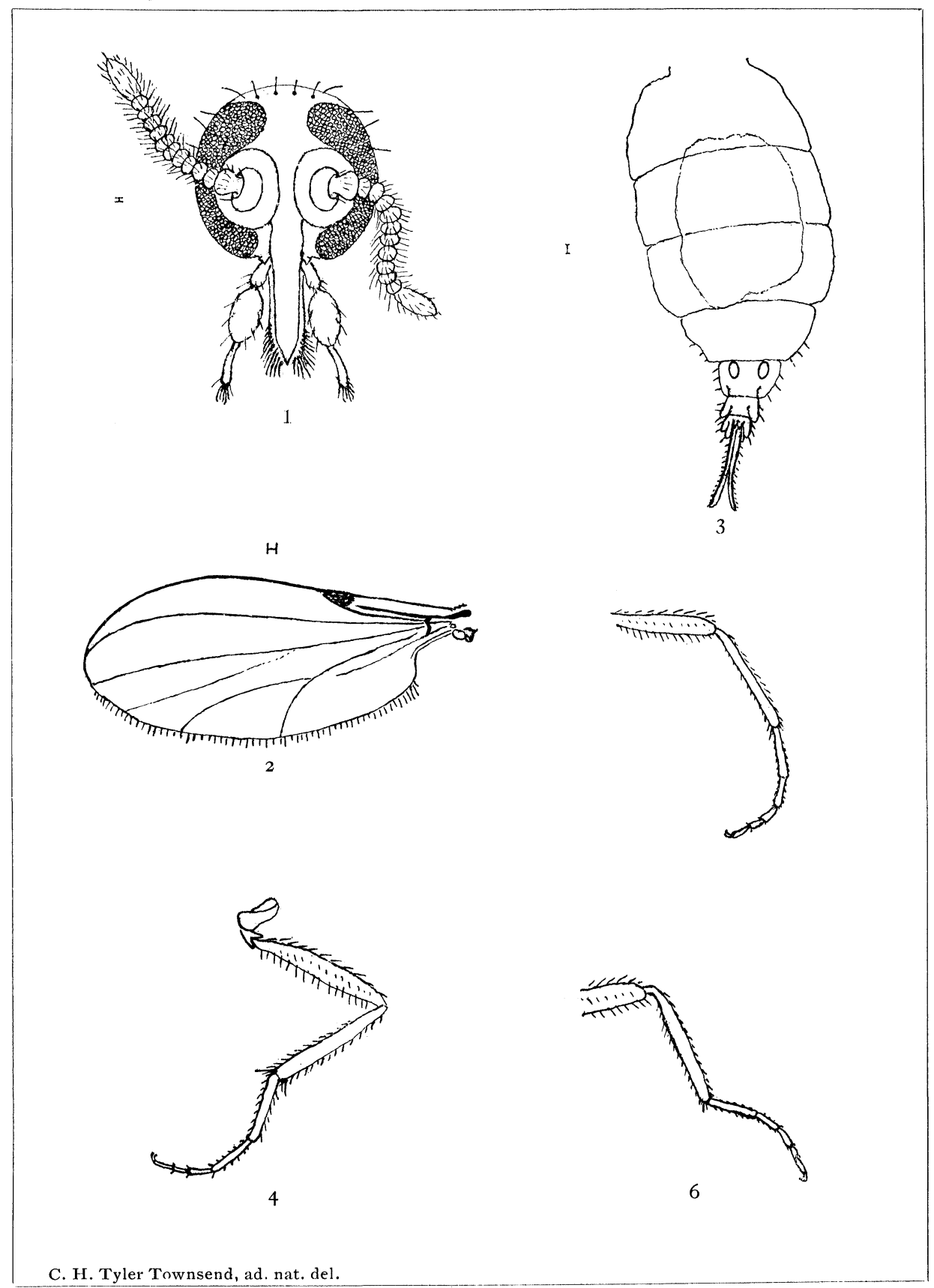

Tersesthes torrens Twns. $q$. 

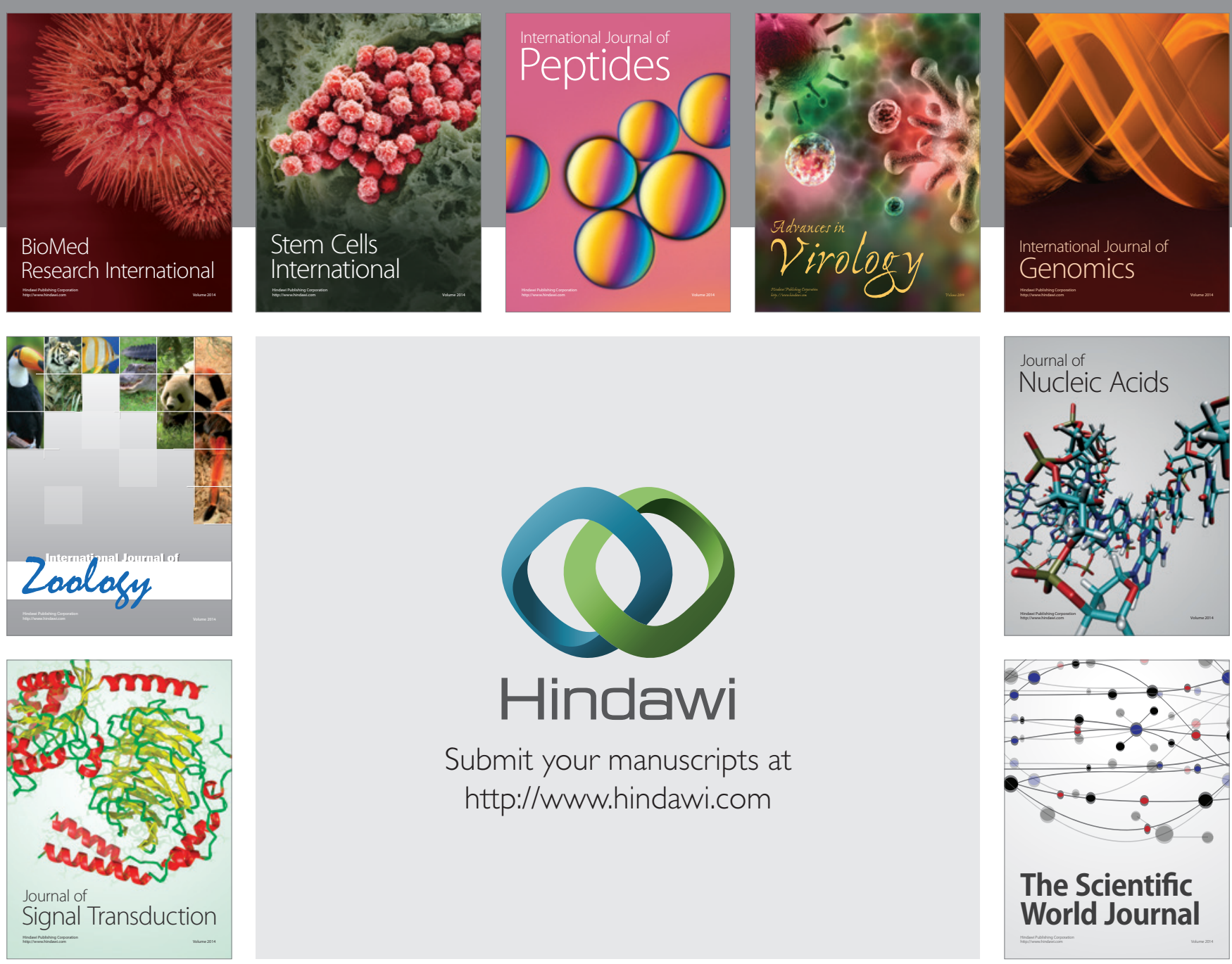

Submit your manuscripts at

http://www.hindawi.com
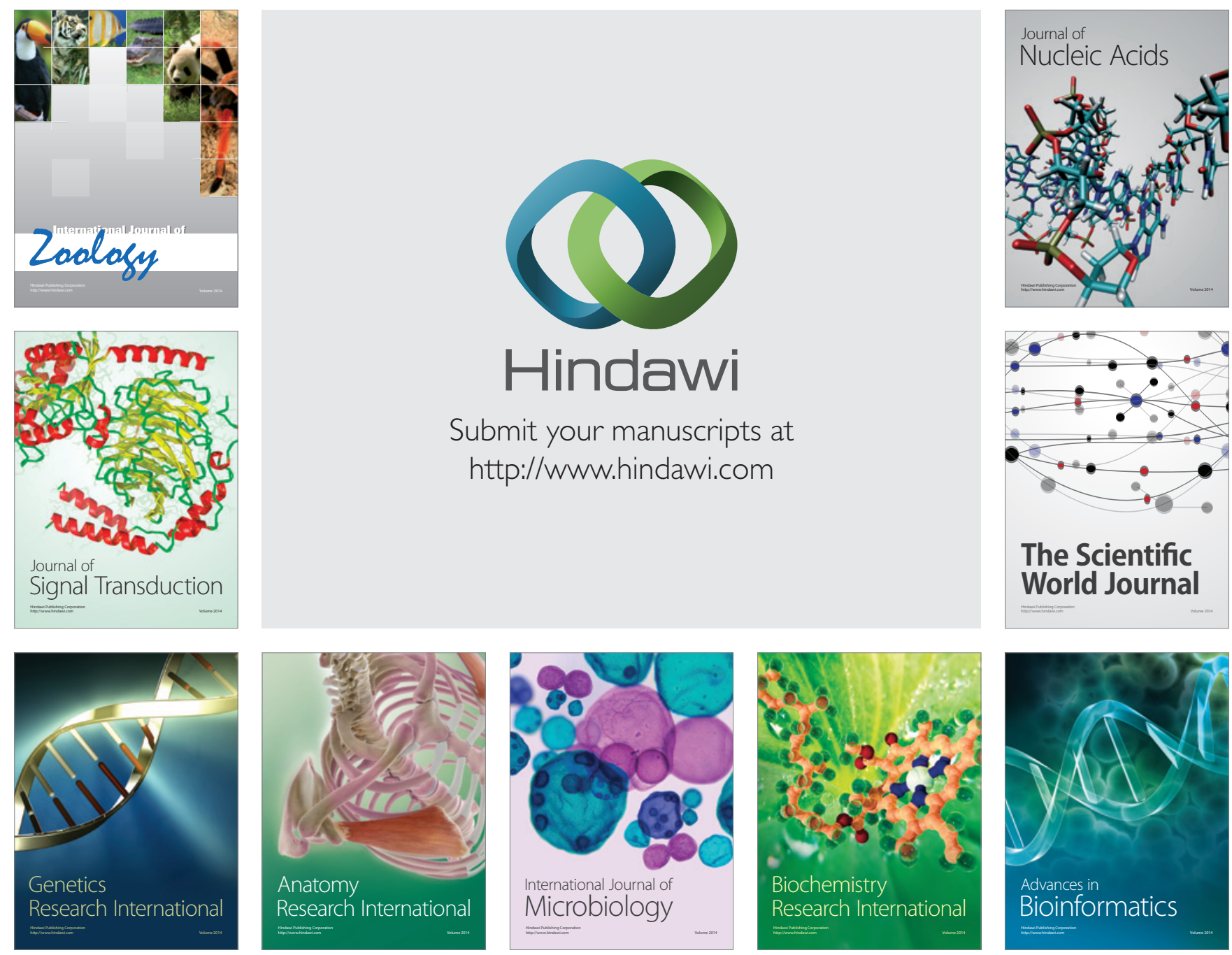

The Scientific World Journal
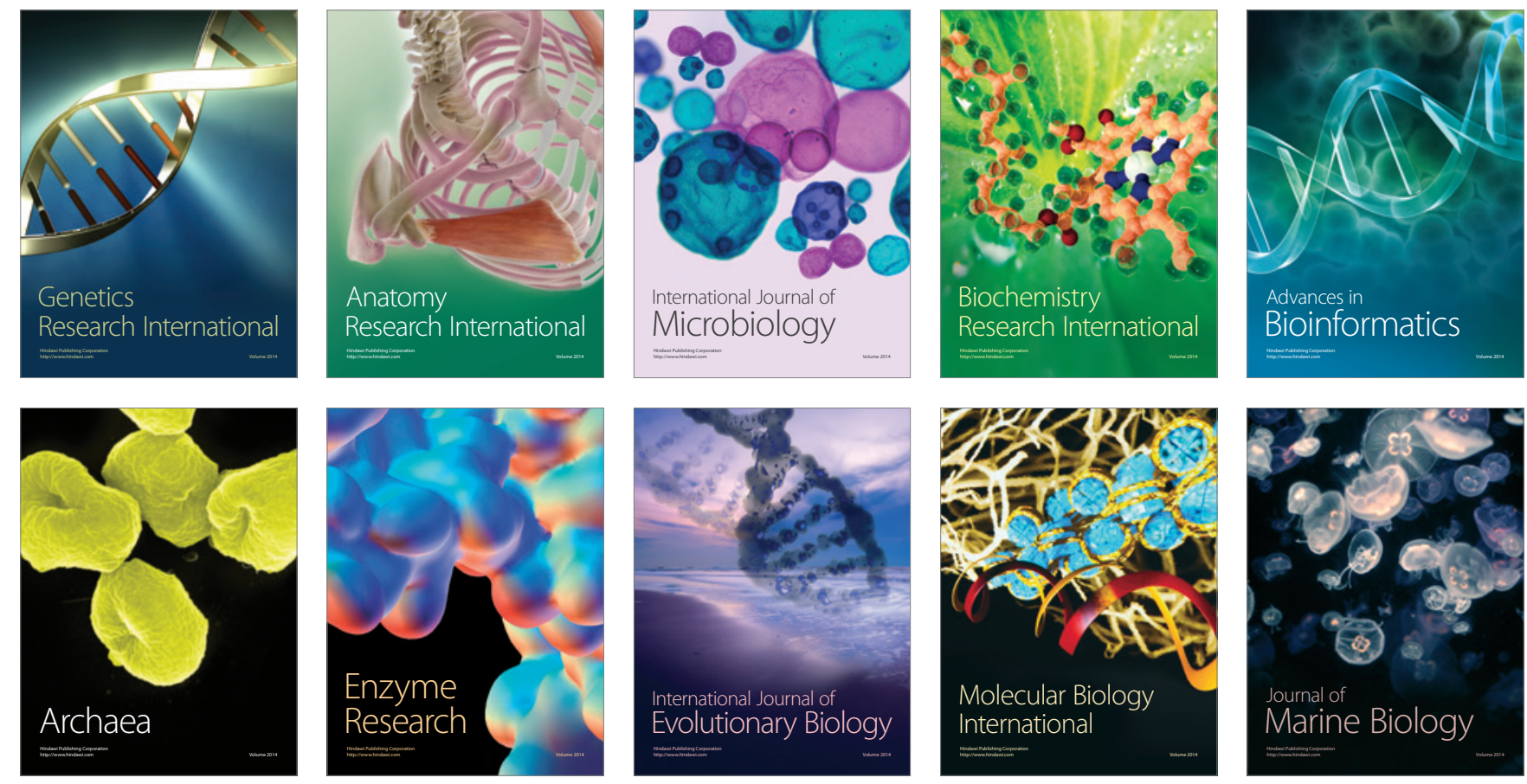